\title{
Félix Máximo López (1742-1821) como autor dramático y musical. Transcripción, estudio y edición de su obra
}

\author{
Autora: Dra. María Luisa Navarro Pascual. \\ Director: Dr. Germán Labrador López de Azcona. \\ Institución: Universidad Autónoma de Madrid. \\ Tribunal: Dr. Paulino Capdepón Verdú (Universidad de Castilla-La Mancha), \\ Dr. Gustavo Sánchez López (Universidad Autónoma de Madrid) y Dra. Ana Contreras \\ Elvira (Real Escuela Superior de Arte Dramático). \\ Calificación: Sobresaliente cum laude.
}

Fecha de la defensa: 23 de octubre de 2020.

\section{Resumen:}

El objeto de estudio de esta tesis es parte de la obra poético-musical realizada por Félix Máximo López (1742-1821), entendidas como tales las obras vocales (villancicos y cánones), las obras de teatro musical (tonadillas), así como la integral de la obra dramáticopoética que ha llegado hasta nosotros. La selección de estas obras viene precedida por el análisis del contexto actual en el que con excepción de su obra para tecla, que ha recibido la atención de algunos investigadores y organistas, el resto de la producción del autor permanecía olvidada e inédita. Así y todo, siendo las obras para tecla las más conocidas, su difusión ha sido también escasa, viéndose recogidas en grabaciones solo algunas de las piezas, siempre las mismas, y permaneciendo las demás también en el olvido.

Es esta una tesis basada en fuentes documentales, habiéndose consultado para su realización más de 200 documentos, de distinto género, entre los que podríamos destacar documentación administrativa, documentación profesional y documentación musical.

El trabajo dictoral está dividido en dos volúmenes, el primero de los cuales contiene el marco teórico de la investigación, así como el estudio de las obras, la bibliografía, las conclusiones y los anexos; el segundo recoge las ediciones, de texto y música, con el pertinente aparato crítico de cada una de ellas. 


\section{TESIS DOCTORALES}

El Volumen I está dividido en tres partes: la primera recoge la biografía del autor, la segunda el estudio de la obra y la tercera las fuentes.

En la Parte primera - Biografía se realiza, a manera de introducción histórica, un bosquejo de lo que era Madrid, ciudad natal del autor, desde la perspectiva de la vida que en ella se desarrollaba, situando como hitos principales las instituciones (Real Capilla, Monasterio de la Encarnación, Monasterio de las Descalzas Reales) y establecimientos públicos (Coliseos de la Cruz y el Príncipe) en los que López realizaba su labor profesional. Comienza esta introducción ofreciendo datos sobre la distribución administrativa de la ciudad, las profesiones a las que se dedicaban sus vecinos, los usos y costumbres, etc. A continuación, se desarrolla la biografía del autor, refrendada tanto por documentación administrativa y profesional, como por la propia visión que de él mismo y su entorno nos ofrece el autor en sus obras. Se incluye el "árbol genealógico” en el anexo.

La Parte segunda - Obra, dividida en cinco capítulos, recoge el estudio de la selección de obras realizada para esta tesis, pasando por el análisis de cada una de ellas y terminando con la edición de las mismas. En cada uno de los capítulos hay una introducción en la que se contextualizan las obras en el entorno en el que se realizaron.

El Capitulo I - Tonadillas, contextualiza las obras en el entorno de los teatros madrileños, situando las compañías, los actores y las características principales de la época en la que se realizaron las tonadillas. Se han agrupado las seis tonadillas en dos categoría: tonadillas de juventud (Las abejas, Los andaluces y El escondite) y tonadillas de madurez (El abogado y la maja, La mesonera y el arriero y La conversación). A continuación, se desarrolla el análisis de cada una de las obras comenzando, en cada caso, por la presentación de una tabla en la que aparece su estructura formal e instrumentación; tras esto, se realiza el análisis de cada una de las partes en las que se constituyen.

En el Capitulo II - Villancicos, tras su contextualización, en la que se establecen las líneas generales del nacimiento y evolución del género, haciendo mención específica a las características propias de la época en la que López compone sus obras, se presenta una tabla en la que se indican, al igual que se hace con las tonadillas, la estructura formal de cada obra (Bartolo, Los presos y Hoy amor se disfraza) y su instrumentación. A continuación, se realiza el análisis de cada uno de los villancicos.

El Capitulo III - Cánones, recoge la descripción de este género de composiciones, desde el surgimiento del mismo hasta la época en la que se sitúa la obra de López, para después trazar las líneas de lo que suponen los cánones en el contexto de la propia obra del autor. Se establecen distintas clasificaciones de estas obras (43 Cánones) según el número de voces, la tesitura, el idioma, los contenidos y la utilización. Se realiza el estudio de los cánones sobre la versión desarrollada de los mismos para, de esta forma, poder recoger todas las características que se pueden expresar en el análisis completo de estas obras, desarrolladas en todas sus voces.

En el Capitulo IV - Lenguaje y práctica musical de López, se recoge el análisis comparativo del conjunto de la obra estudiada, trazando las bases para establecer las características propias del autor en su lenguaje y praxis musical, desde el punto de vista de la tímbrica, dinámica, textura, armonía, ornamentación, etc. 


\section{TESIS Doctorales}

El Capitulo V-Obra poético-dramática, contextualiza la tipología de estas obras dentro del teatro breve y la poesía de la época en que fueron escritas, además de situarlas en las tertulias y los salones del momento. Se desarrolla el concepto de "teatro familiar", como derivado del "teatro doméstico". El análisis de las obras, recogidas en el volumen titulado Obras poéticas, líricas y cómicas..., es descriptivo, intentando establecer las características generales y extrayendo la información personal que se utilizará, con posterioridad, tanto en la recreación de la biografía del autor como para trazar algunas líneas sobre su personalidad.

La Parte tercera - Tradición textual de la obra de F. M. López. Estudio y sistematización, es en la que se describen y analizan las fuentes documentales que contienen las obras del autor. Se da noticia de las obras que han llegado hasta nosotros, situándolas en las instituciones que las custodian (Biblioteca Nacional de España, Biblioteca Histórica de Madrid, British Library, etc.) y se hace mención de las que tenemos idea de su existencia por las distintas fuentes secundarias que las recogen, aún sin tenerlas físicamente en la actualidad. Con todos los datos, se desarrolla una relación de obras del autor, a manera de apuntes para un futuro catálogo, organizada en secciones y subsecciones. A continuación, se realiza el estudio pormenorizado de las fuentes que se han utilizado para realizar la investigación.

El Volumen II contiene las ediciones de las obras estudiadas. En una primera parte están recogidas las ediciones musicales, precedidas de un aparato crítico, pensando en ellas como ediciones prácticas es decir, pretendiendo ofrecer una versión de las obras que pueda ser fácilmente interpretada a día de hoy. La segunda parte recoge la edición de los textos, tanto de las obras poético-dramáticas como de los villancicos, cánones y apuntes de teatro de las tonadillas (libretos), precedidas también del aparato crítico pertinente. 